\title{
Correlation between Nodule Ultrastructure and Ability to Produce Stem Nodules in Aeschynomene spp.
}

\author{
Steven J. Stegink \\ Southern Regional Research Center, USDA-ARS, P. O. Box 19687, \\ New Orleans, LA 70179, U.S.A. \\ and \\ Kevin C. Vaughn \\ Southern Weed Science Laboratory, USDA-ARS, P. O. Box 350, \\ Stoneville, MS 38776, U.S.A.
}

Accepted June 20, 1987

Some species of the genus Aeschynomene have the rare ability to produce nodules on both roots and stems (Eaglesham and Szalay 1983, Alazard 1985). The ability to produce stem nodules may be advantageous to a plant, especially one growing in areas that are periodically flooded because a constant supply of $\mathrm{N}_{2}$ and $\mathrm{O}_{2}$ is available, even during flooded conditions. Additionally, the stem nodule cortical tissue is photosynthetic (Yatazawa and Yoshida 1979, Vaughn and Elmore 1985), so a plant does not have to expend much energy transporting photosynthetic products in order to sustain fixation. Alazard (1985) found that Aeschynomene species which produce stem nodules are infected by Rhyzobia that belongs to inoculation groups different from Rhizobia which infect Aeschynomene species that produce only root nodules. Very little has been reported on the structure of nodules formed following infection, and virtually all that is known concerns itelf with iust Aeschynomene indica (Arora 1954, Vaughn and Elmore 1985, Yatazawa et al. 1984).

Previous data in our laboratory have shown that a correlation exists between root nodule structure and the nitrogen containing compound transported from the nodule (Stegink et al. 1987). In this report, we investigated if a correlation exists between root nodule ultrastructure and the ability of Aeschynomene species to make stem nodules. Our data indicate that species which produce stem nodules exhibit remarkably similar root nodule ultrastructure. Those species which produce only root nodules produce nodules with bacteroids of markedly different ultrastructure than the species which produce stem nodules.

\section{Materials and methods}

Plant material Seeds of a number of Aeschynomene species (Table 1) were the generous gift of Dr. A. E. Kretschmer (IFAS, Homestead, FL) and Dr. G. E. Templeton (Dept. Plant Pathol., U. Arkansas, Fayetteville, AR). Seeds were scarified by nicking with a razor blade and germinated in either Sloger's solution (Sloger 1969) in vermiculite or a potting mixture, consisting of peat, perlite and vermicultie $(3: 1: 1)$. Plants were inoculated from nodule crushes of Aeschynomene inica, broth cultures of a rhizobia from $A$. virginica nodules from the USDA culture collection, or by trapping airborne Rhizobium on growing plants in the greenhouse without supplemental nitrogen. Nodules were picked for microscopy only when a deep pink coloration, indicative of high levels of leghemoglobin, was evident.

Microscopy Nodule segments were fixed, processed, and examined by light and electron 
microscopy using the procedures of Vaughn and Elmore (1985). Cross-sections from at least three different nodules were examined for each species. The results given for a particular species were consistent among the nodules sampled.

\section{Results and discussion}

Some of the characteristics of nodule structure are common among all of the Aeschynomene species surveyed. All of the nodules produced by the various Aeschynomene species are spherical or nearly so. Unlike most species, where the nodules may arise at many points along the root, Aeschynomene nodules were found exclusively in areas where lateral roots had

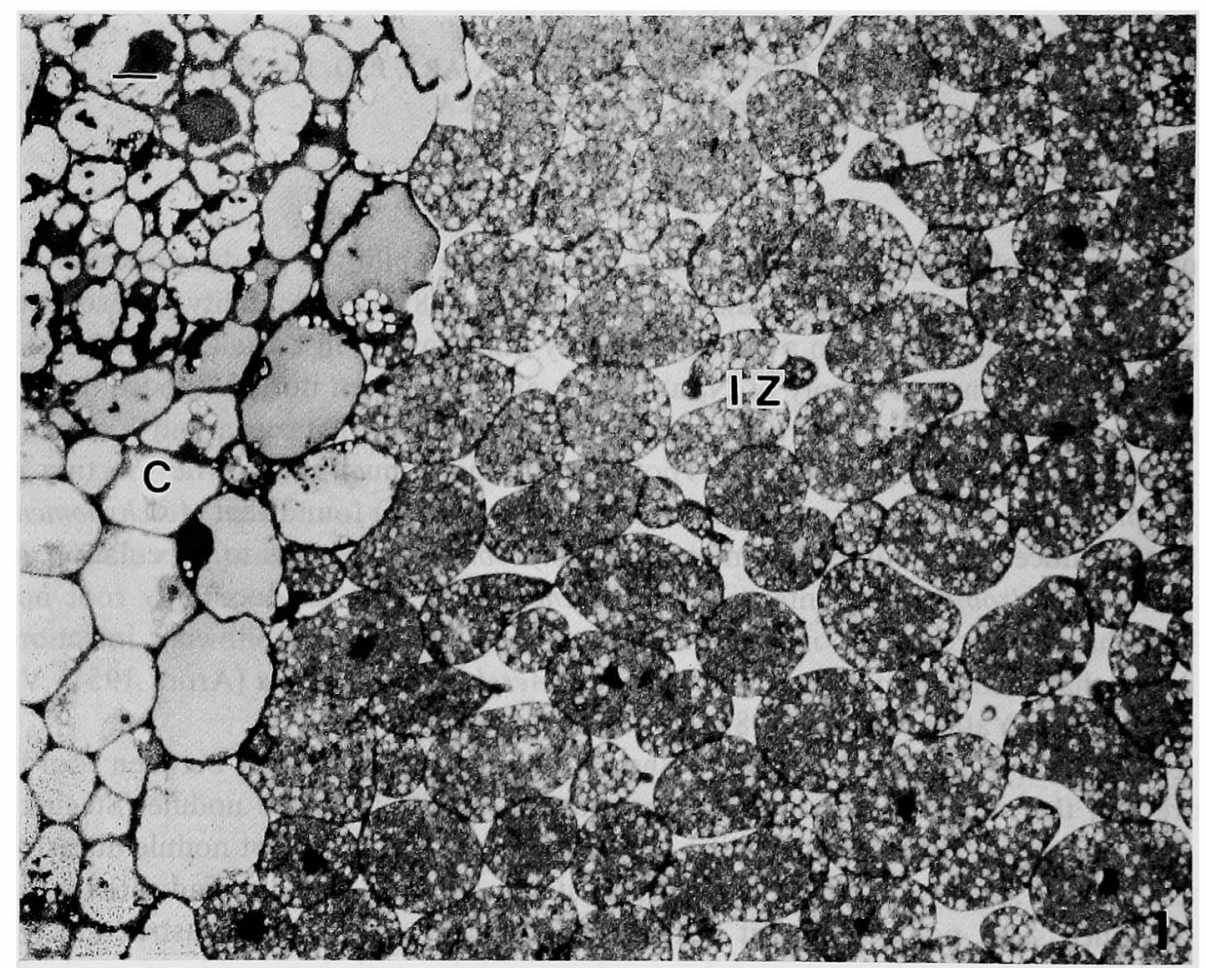

Fig. 1. Light micrograph of sections through the nodules of Aeschynomene americana. Note the homogeneous infected zone (IZ) surrounded by uninfected cortical cells (C). The layer of cortical cells next to the infected zone are more densely stained than the other cortical layers. Bar $=20 \mu \mathrm{m}$.

protruded from the taproot (Arora 1954, Vaughn and Elmore 1985). These are also characteristics of peanut root nodules (Chandler 1978), which Aeschynomene nodules closely resemble in many characteristics. Corby et al. (1983) have described this as the "Aeschynomenoid type" nodule. All of the species produced nodules in which the infected zone was filled only with infected cells (Fig. 1). Uninfected interstitial cells, commonly found in ureide-transporting species (Dart 1977, Vaughn 1985, Stegink et al. 1987) and in some amidetransporting species (Dart 1977, Stegink et al. 1987) are not present in any of Aeschynomene spp. examined. Dart (1977) observed that infection threads are absent in nodules without interstitial cells. Consistent with this observation, none of the Aeschynomene species surveyed here produces any infection threads. Rather, the infecting bacteria appear to move along the middle lamellae and then penetrate into the cell by a "pinocytotic" mechanism (Fig. 2A). 


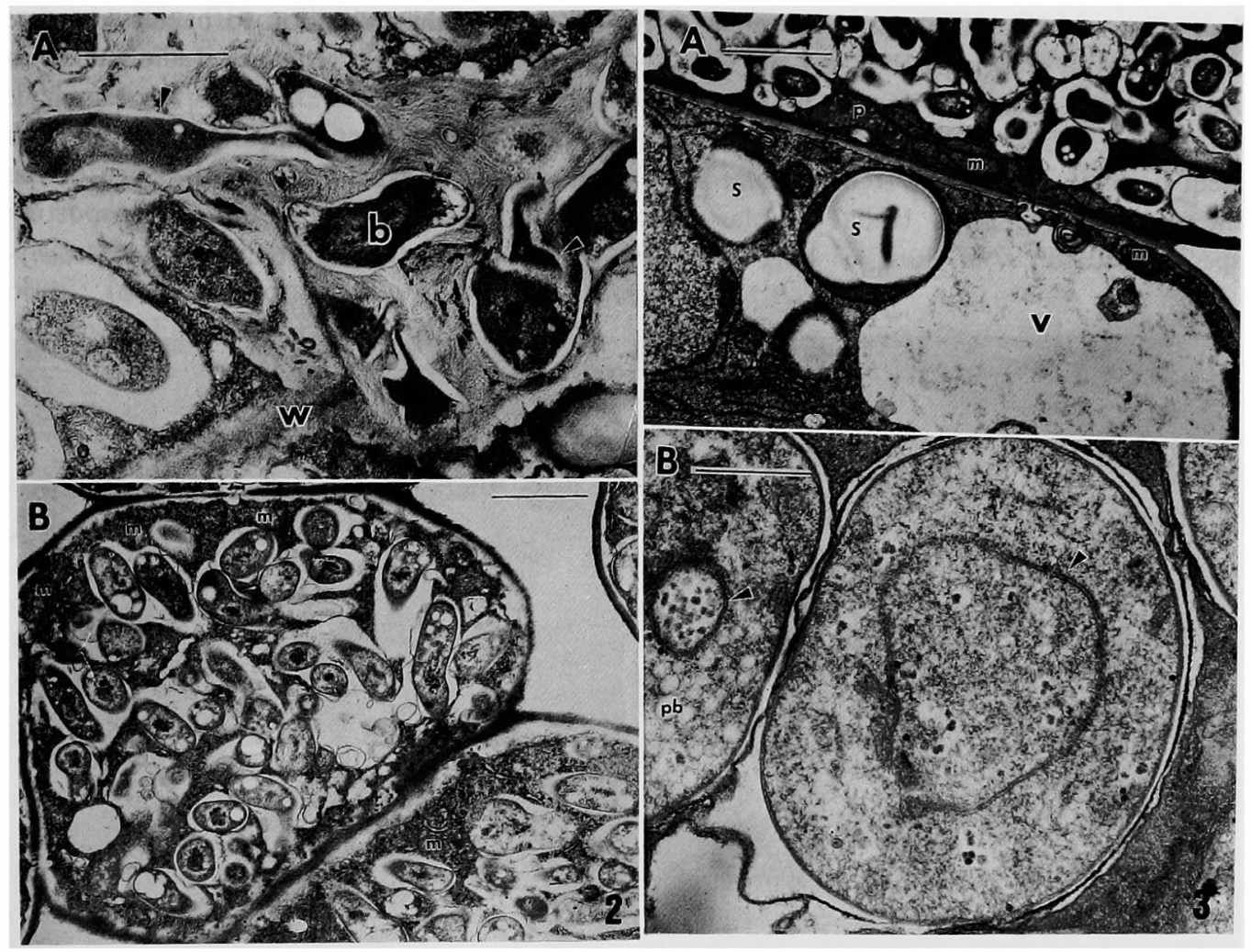

Figs. 2-3. 2A, in a root nodule from A. americana, the bacteria (b) and bacteria in the transition from bacteria to bacteroids (arrows) are present in the wall (w) of the host cell. 2B, root nodules of $\boldsymbol{A}$. brasiliana with mitochondria $(\mathrm{m})$ located primarily at edge of the cells. $\mathrm{b}=$ bacteroid. $\mathrm{Bar}=$ $1.0 \mu \mathrm{m}$ in $\mathrm{A}, 2.0 \mu \mathrm{m}$ in B. $3 \mathrm{~A}$, root nodule of $A$. fiuminensis showing the interface between the cortical and the infected cells. Note the poorly-developed, starchless plastids ( $\mathrm{p}$ ) in the infected cell in contrast to the plastids with abundant starch ( $\mathrm{s}$ ) in the cortical cells. $\mathrm{v}=$ vacuole, $\mathrm{m}=$ mitochondrion. 3B, bacteroids from a root nodule of $A$. scabra. The oval bacteroid is enclosed by a single peribacteroid membrane. The inner membrane has extensive invaginations (arrows) that extend throughout the bacteroid cytoplasm. Polyhydroxybutyrate deposits $(\mathrm{pb})$ are found in clusters. $\mathrm{Bar}=2.0 \mu \mathrm{m}$ in $\mathrm{A}, 0.5 \mu \mathrm{m}$ in $\mathrm{B}$.

Table 1. Summary of the comparisons of bacteroid ultrastructure in root nodules of various Aeschynomene species

\section{Bacteroid ultrastructure}

Stem nodulating-species
A. indica
A. scabra
A. evenia
A. sensitiva
A. rudis

Non-stem nodulationg species
A. americana
A. brasiliana
A. fluminensis
A. virginica

Spheres with well developed internal membranes Spheres with well developed internal membranes Spheres with well developed internal membranes Spheres with well developed internal membranes Spheres with well developed internal membranes

Pleomorphic, small internal extensions

Ovals

Rods, dense inclusions

Pleomorphic, very small internal extensions 
Examples of bacteria in the wall, and bacteria undergoing the transition to bacteroids were observed even in a single thin section (Fig. 2A). A similar infection sequence was observed in Aeschynomene indica by Vaughn and Elmore (1985).

The distribution and structure of the organelles of the host plant are quite similar in both stem nodulators and non-stem nodulators. Mitochondria and plastids rim the edge of the infected cells (Fig. 2B). Unlike the plastids in infected cells of many other amide-transporting species (Vaughn et al. 1982, Stegink et al. 1987), plastids in the infected cells of Aeschy-
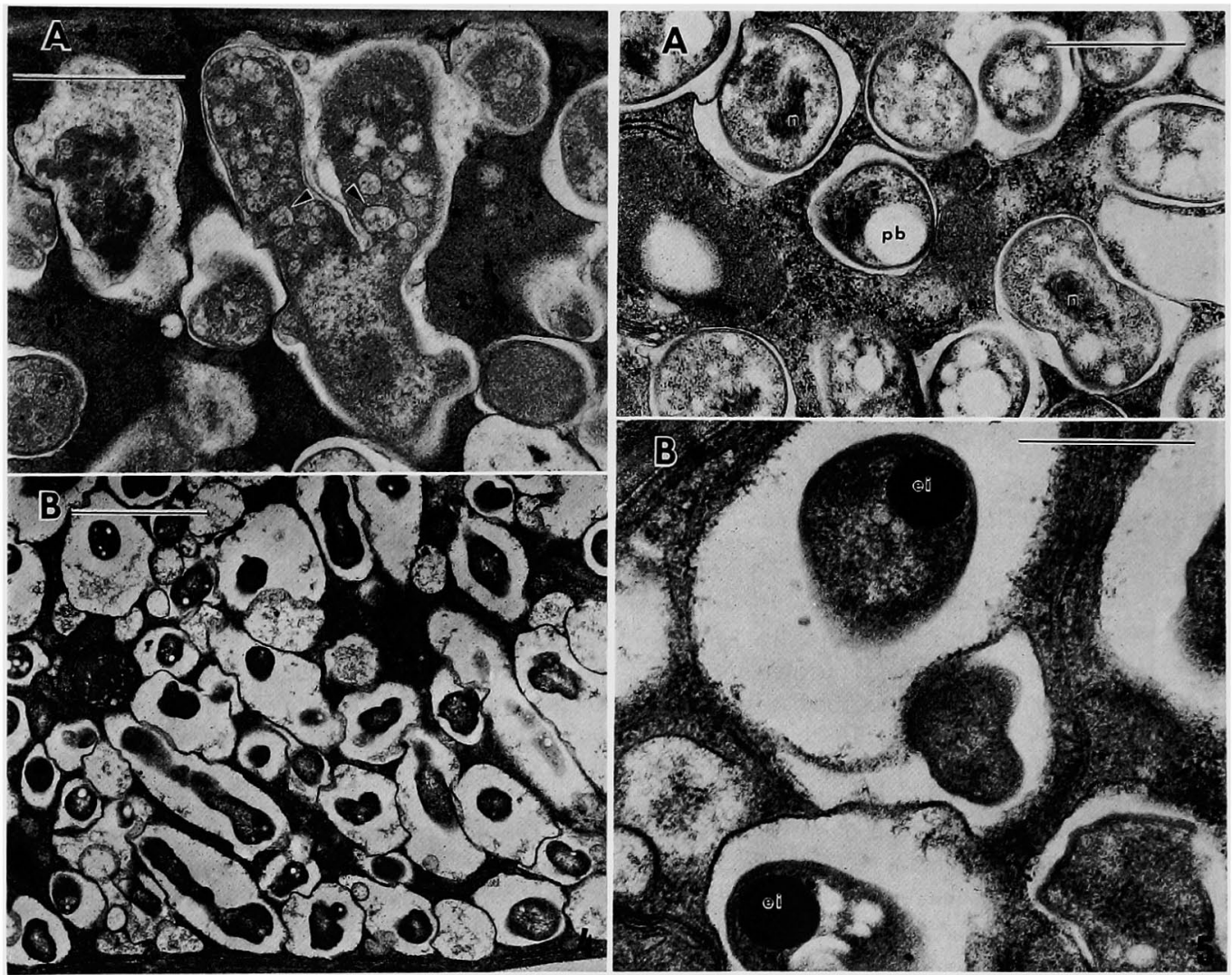

Figs. 4-5. 4A, bacteroids of $A$. americana exhibit a characteristic $\mathrm{Y}$ shape morphology and small inner membrane invaginations (arrows). 4B, bacteroids of $A$. fluminensis are seen both in longsection and cross-section. These bacteroids are typical rod shaped with little internal membrane invaginations. $\mathrm{Bar}=1.0 \mu \mathrm{m}$ in $\mathrm{A}, 2.0 \mu \mathrm{m}$ in B. $5 \mathrm{~A}$, bacteroids of $A$. brasiliana are relatively simple structurally, with deposits of polyhydroxybutyrate $(\mathrm{pb})$ and accumulation of DNA arranged in a central mass like nucleus (n). 5B, bacteroids of $A$. fluminensis with electron-opaque inclusions (ei). These inclusions were only noted in A. fluminensis. $\mathrm{Bar}=1.0 \mu \mathrm{m}$ in $\mathrm{A}, 0.5 \mu \mathrm{m}$ in $\mathbf{B}$.

nomene are generally starchless, although plastids from the uninfected cortical tissue often have starch (Fig. 3A). Other than a centrally-localized nucleus (Vaughn and Elmore 1985), none of the other organelles (endoplasmic reticulum, Golgi bodies, vesides, vacuole) are particularly salient in the cells of the infected zones of the mature nodule.

Despite the similarities among the nodules of Aeschynomene for the nodule characteristics described above, the bacteroids from root nodules of stem nodulating species are ultrastructurally distinct from those of stem-nodulating species (Table 1). The bacteroids of all of these stem-nodulating species are spherical and generally occur singly, surrounded by a peribacteroid 
membrane (Fig. 3B). Unlike most bacteroids, the bacteroids of these stem-nodulating species contain elaborate invaginations of the bacteroid membrane (Fig. 3B). Frequently, inclusions (polyphosphate and polyhydroxybutyrate bodies) and aggregations of DNA (nucleoids) may be observed. These observations are also in agreement with the previous observations of root and stem nodules of Aeschynomene indica alone (Vaughn and Elmore 1985, Yatazawa et al. 1984, Legocki et al. 1983).

Bacteroids of the non-stem nodulating species are of many different morphologies. Pleomorphic (note the cross-section of the bacteroids with a characteristic " $Y$ " shape, Fig. 4A). rod-shaped (Fig. 4B), and spherical or ovular (Fig. 5A) morphologies are noted among the species that do not stem nodulate. Only the pleomorphic bacteroids have the membrane invaginations characteristic of the stem-nodulating species. In the bacteroids of $A$. fluminensis, some very different kinds of inclusion bodies, apparently membrane-bound, are noted (Fig. 5B). None of these have bacteroids with the structure found on the stem-nodulating species.

A consistent ultrastructure is found amongst species that produce stem-nodules although the Rhizobium that produces stem nodules and all appear to belong to the same inoculation group (Alazard 1985, Eaglesham and Szalay 1983). However, one species of Rhizobium can produce a bacteroid of grossly different morphology depending upon the species infected (Dart 1977), e.g. a single Rhizobium strain produced rod-shaped in mung bean nodules but oval bacteroids in peanut nodules. The factors which determine bacteroid ultrastructure in root nodules of stem-nodulating Aeschynomene species are not known. In distinction from the example in which root nodule ultrastructure correlates with root nodule metabolism (Stegink et al. 1987), no metabolic differences are known to exist among root nodules of the various Aeschynomene species, surveyed in this study. In the stem nodules, the bacteroids have the advantage of having a supply of fixed $\mathrm{CO}_{2}$ from the nodule tissue itself and the $\mathrm{CO}_{2}$ supplied by the adjacent foliage, in addition to an almost unlimited supply of atmospheric $\mathrm{N}_{2}$. In this ideal situation, it is possible that the extensive membrane invaginations allow for greater numbers of reduction sites and higher rates of $\mathrm{N}_{2}$ fixation. However, the presence of some membrane invaginations in two non-stem nodulating species makes even this conclusion tenuous. Although our survey of the Aeschynomene species is not exhaustive, the number of species of both stem nodulating and non-stem nodulating types surveyed here indicates that the ultrastructure of the root nodules may serve as a guide for screening species that might, under some conditions, also produce stem nodules.

\section{Summary}

Certain features of bacteroid ultrastructure in root nodules of Aeschynomene spp. correlate with the ability of the plant to produce stem nodules. Bacteroids of root nodules of stem-nodulationg species are relatively complex structurally and contain extensive invaginations of the membranes, clusters of DNA organized into nucleoids, and several electron opaque inclusions. The bacteroids in all of the stem-nodulating Aeschynomene species examined are generally enclosed singly in peribacteroid membranes and are oval-shaped. The bacteroids of non-stem nodulating species are varied in morphology (pleomorphic, rods and near ovals) and contain much less extensive invaginations of the membranes than the stem nodulating species. Some characteristics, such as the absence of interstitial cells and lack of infection threads, are found throughout the Aeschynomene root nodules examined. These data indicate that bacteroid ultrastructure might seve as structural clue as to potential stem-nodulating species and may relate to an underlying metabolic difference between stem-nodulating and non-stemnodulating spp. 


\section{Acknowledgements}

Thanks are extended to R. H. Jones, L. E. Clarke, and M. R. Giachelli for excelient technical assistance, to A. E. Kretchmer and G. E. Templeton for Aeschynomene seeds, to T. B. Moorman for assistance with growth and culture of Rhizobium spp., to C. A. Henson and A. R. Lax for constructive comments, and to A. G. Louwerens for all typing tasks. Mention of a trademark, proprietary product, or vendor does not constitute a gurarantee or warranty of the product by the U. S. Dep. Agric. and does not imply its approval to the exclusion of other products or vendors that may also be suitable.

\section{References}

Alazard, D. 1985. Stem and root nodulation in Aeschynomene spp. Appl. Environ. Microbiol. 50: 732-734. Arora, N. 1954. Morphological development of the root and stem nodules of Aeschynomene indica L. Phytomorphology 4: 211-216.

Chandler, M. R. 1978. Some observations on infection of Arachis hypogea L. by Rhizobium. J. Exp. Bot. 29: 749-755.

Corby, H. D. L., Pollhill, R. M. and Sprent, J. I. 1983. Taxonomy. In Nitrogen Fixation 3: Legumes (W. J. Boughton, ed.). pp. 1-35. Clarendon Press, Oxford.

Dart, P. J. 1977. Infection and development of leguminous nodules. In A Treatise on Dinitrogen Fixation III. Biology (R. W. Hardy and W. S. Silver, eds.). pp. 377-472. John Wiley, New York.

Eaglesham, A. R. J. and Szalay, A. A. 1983. Aerial stem nodules on Aeschynomene spp. Plant Sci. Lett. 29: 265-272.

Legocki, R. P., Eaglesham, A. R. J. and Szalay, A. A. 1983. Stem nodulation in Aeschynomene: a model system for bacterium-plant interactions. In Molecular Genetics of the Bacteria-Plant Interactivity (A. Puhler, ed.). pp. 210-219. Springer Verlag, New York.

Newcomb, W. 1981. Nodule morphogenesis and differentiation. In Biology of the Rhizobiaceae (K. L. Giles and A. G. Atherley, eds.) pp. 247-298. Academic Press, New York.

Sloger, C. 1969. Symbiotic effectiveness and $\mathrm{N}_{2}$ fixation in nodulated soybean. Plant Physiol. 44: 1666-1668.

Stegink, S. J., Vaughn, K. C. and Verma, D. P. S. 1987. Antigenic similarity in urate oxidases of major ureideproducting legumes and its correlation with the type of peroxisome in uninfected cells of nodules. Plant Cell Physiol. 28: 387-396.

Vaughn, K. C. 1985. Structural and cytochemical characterization of three specialized peroxisome types in soybean. Physiol. Plantarum 64: 1-12.

-, Downs, B. D. and Wilson, K. G. 1980. Ultrastructural and cytochemical studies of "air blisters" in Pilea Cadierei Gagnep. and Guillaumin. Annals of Bot. 46: 221-224.

-, Duke, S. O., Duke, S. H. and Henson, C. A. 1982. Ultrastructural localization of urate oxidase in nodules of Sesbania exaltata, Glycine max, and Medicago sativa. Histochem. 74: 309-318.

- and Elmore, C. D. 1985. Ultrastructural characterization of nitrogen-fixing stem nodules on Aeschynomene indica. Cytobios 42: 49-62.

Yatazawa, M. and Yoshida, S. 1979. Stem nodules in Aeschynomene indica and their capacity of nitrogen fixation. Physiol. Plant. 45: 293-295.

-, - and Maeda, E. 1984. Fine structure of root nodules of Aeschynomene indica L. Soil Sci. Plant Nut. 30: $405-416$. 